\title{
Changes in food supply in Mediterranean countries from 1961 to 2001
}

\author{
Reina Garcia-Closas, Antoni Berenguer and Carlos A González* \\ Department of Epidemiology, IDIBELL-Catalan Institute of Oncology (ICO), Av Gran Via s/n, km 2,7, \\ ES-08907 L'Hospitalet, Barcelona, Spain
}

Submitted 12 October 2003: Accepted 11 May 2005

\begin{abstract}
Objective: To describe geographical differences and time trends in the supply of the most important food components of the traditional Mediterranean diet.

Design: Food supply data collected from national food balance sheets for the period 1961-2001.

Setting: Selected Mediterranean countries: Spain, Italy, France, Greece, Algeria, Morocco, Tunisia and Turkey.

Results: Differences of almost 30-fold and five-fold were found in the supply of olive oil and fruits and vegetables, respectively, among the Mediterranean countries studied during the 1960s. A favourable increasing trend for the supply of fruit and vegetables was observed in most Mediterranean countries. However, an increase in the supply of meats and dairy products and a decrease in the supply of cereals and wine were observed in European Mediterranean countries from 1961 until 2001. Only in African and Asiatic Mediterranean countries were cereals the base of food supply. During the 1990s, Greece's food supply pattern was closest to the traditional Mediterranean diet, while Italy and Spain maintained a high availability of fruits, vegetables and olive oil, but were losing the other typical components. Among African and Asiatic Mediterranean countries, only Turkey presented a traditional Mediterranean dietary pattern except with respect to olive oil, the supply of which was very low. France showed a Western dietary pattern, with a high supply of animal products and a low supply of olive oil.

Conclusions: Dietary supplies in the Mediterranean area were quite heterogeneous in the 1960s and have experienced a process of Westernization, especially in European Mediterranean countries.
\end{abstract}

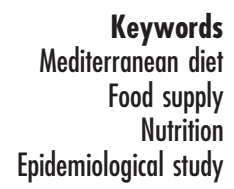

Franean diet

ood supply

Epidemiological study
The Mediterranean diet is accepted to be a healthy pattern of intake as well as an expression of lifestyle and a cultural model ${ }^{1}$. The concept of the Mediterranean diet was defined as the food patterns and dietary habits found in some olive-growing areas of the Mediterranean Basin in the early 1960s, and at present a wide consensus of experts recognise that the definition needs to be updated $^{2}$. Common components of the traditionally defined Mediterranean diet are: abundant intake of plant foods (fruits, vegetables, breads, other forms of cereals, beans, nut and seeds); olive oil as the principal fat source; moderate consumption of wine; low to moderate consumption of cheese, yoghurt, fish, poultry and eggs; and low consumption of red and processed meat $^{1,2}$.

The Seven Countries Study ${ }^{3}$ was the first investigation to be published highlighting the possible health benefits of the Mediterranean diet on death and coronary heart disease. Since then, a growing body of evidence has shown that the traditional Mediterranean diet is associated with low rates of both chronic diseases ${ }^{4-8}$ and premature death ${ }^{9}$. Original observations on possible health benefits of the Mediterranean diet were done in Naples and Crete, and led Ancel Keys to talk about the 'good Mediterranean diet $^{10}$. The dietary patterns found in these two small geographical areas of the Mediterranean region may have influenced many attempts to define the Mediterranean diet as a unique entity. But, even though they have a common core, dietary habits in the Mediterranean area are far from homogeneous ${ }^{11,12}$.

The main objective of the present paper is to describe geographical differences and time trends in the supply of the most important food components of the traditional Mediterranean diet in four European Mediterranean countries - Spain, Italy, France and Greece - and in four African or Asiatic Mediterranean countries - Algeria, Morocco, Tunisia and Turkey. Data obtained from food balance sheets (FBSs) were used for this purpose since the FBS is a valid tool to make geographical comparisons as well as to analyse temporal trends ${ }^{13,14}$. 


\section{Methods}

Annual food availability in each country studied during the period 1961-2001 was obtained from FBS data compiled by the Food and Agricultural Organization (FAO) of the United Nations $^{15}$. To estimate food supply available for human consumption, the yearly total quantity of foodstuffs produced in a country is added to the total quantity imported; then the total quantities exported, fed to livestock, used for seed, put to manufacture for food and non-food uses, and lost during storage and transportation are subtracted from the first figure, and the resulting amount is adjusted to any change in stocks that may have occurred during the specified year. Per capita supply of a food in a given country is then obtained by dividing the respective quantity by the population size of the country. Data on per capita food supply is expressed by the FAO in terms of $\mathrm{kg}$ of food per person per year. For better understanding and comparison of figures with other data sources, availability in the present article is presented as $g$ of food per person per day.

Geographical differences and temporal trends in food supply were analysed for the following food groups: fruits, vegetables, cereals, olive oil, other vegetable oils and animal fat, wine and other alcoholic beverages, milk and dairy products (excluding butter), fish and seafood, meat (including red meat and poultry), and energy from animal products. Graphs for trends on availability are shown.

\section{Results}

\section{Fruits}

Differences of almost five-fold were found in fruit availability among Mediterranean countries in the 1960s, with the highest values being found in Greece, Turkey and Italy, and the lowest in Algeria and Morocco. During the period 1961-2001, fruit supply increased steadily in all Mediterranean countries except Turkey. This increment ranged from 9\% in Greece to 134\% in Spain. In 2001, fruit supply was highest in Greece, Italy and Spain (336398 g person $^{-1}$ day $^{-1}$ ) and lowest in Algeria and Morocco (135 g person $^{-1}$ day $^{-1}$ ) (Fig. 1).

\section{Vegetables}

Also, vegetable availability differed almost five-fold among Mediterranean countries in the 1960s. It was very high in Spain, France, Turkey, Italy and Greece, and very low in Algeria and Morocco. Vegetable availability increased 35174\% from 1961 to 2001 in Mediterranean countries, except in Spain and France. In 2001, figures ranged from 231 g person $^{-1}$ day $^{-1}$ (Algeria) to more than 400 g person $^{-1}$ day $^{-1}$ (Turkey, Italy, Tunisia and Spain), with the highest supply found in Greece ( $744 \mathrm{~g}_{\text {person }}{ }^{-1} \mathrm{day}^{-1}$ ) (Fig. 2).

\section{Cereals}

Throughout the period 1961-2001, Turkey and Morocco presented the highest levels of cereal supply while Spain and France presented the lowest. Overall, cereal availability increased during this period in African and Asiatic countries and decreased in European countries of the Mediterranean area, especially Spain (Fig. 3).

\section{Olive oil, other vegetable oils and animal fats}

Almost 30-fold differences in olive oil supply were found among Mediterranean countries during the 1960s, being very high in Greece but very low in France and most of the African and Asiatic Mediterranean countries studied. During the surveyed period, olive oil supply increased slightly in Greece, Spain and Italy. Differences between countries remained constant, with very low supplies in France and in African and Asiatic Mediterranean countries $\left(<5\right.$ g person $^{-1}$ day $^{-1}$ in 2001) except Tunisia; intermediate

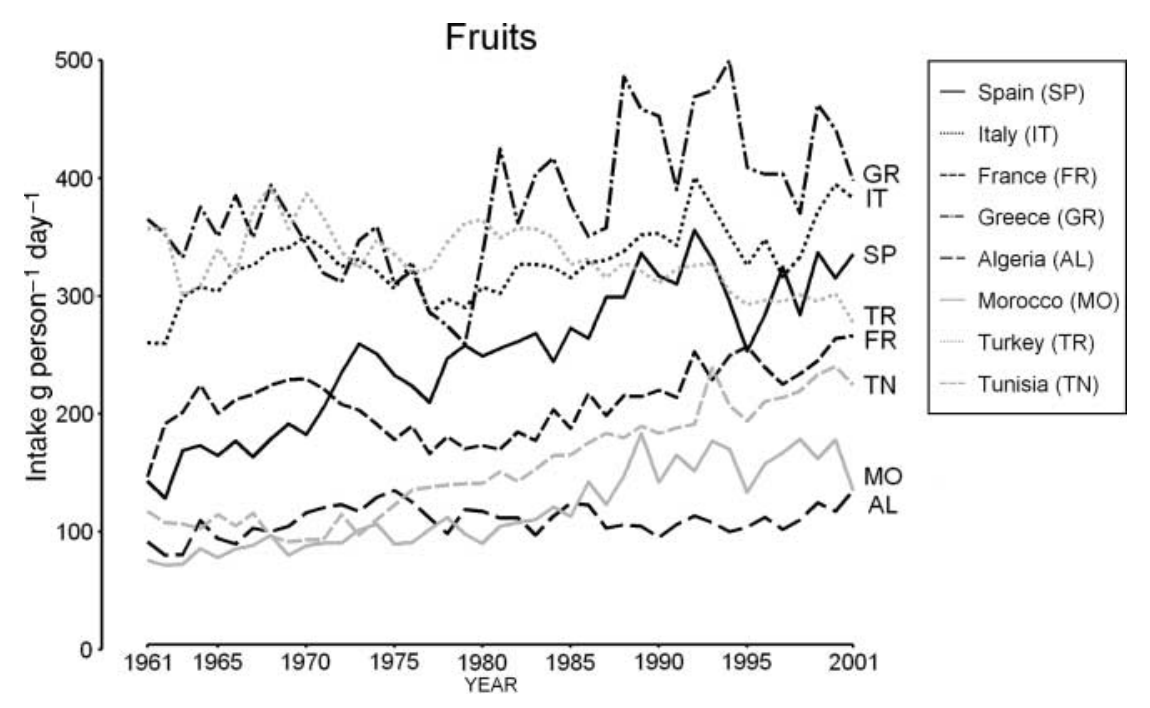

Fig. 1 Fruit supply in selected Mediterranean countries (European, African and Asian) from 1961 to 2001 (source: Food and Agriculture Organization food balance sheets) 


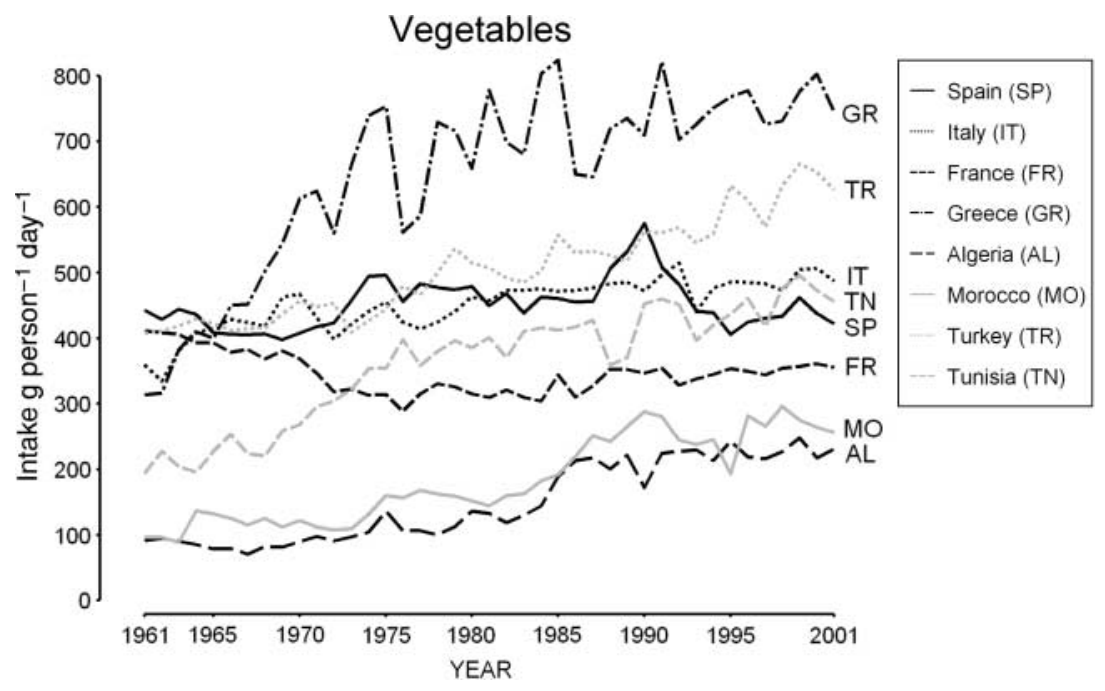

Fig. 2 Vegetable supply in selected Mediterranean countries (European, African and Asian) from 1961 to 2001 (source: Food and Agriculture Organization food balance sheets)

supply values in Spain, Italy and Tunisia (24-36g pers $\mathrm{on}^{-1} \mathrm{day}^{-1}$ in 2001); and high supply values in Greece (51 $\mathrm{g}$ person ${ }^{-1}$ day $^{-1}$ in 2001) (Fig. 4). When looking at vegetable oils other than olive oil (data not shown), a very high increase was observed in all Mediterranean countries, from supply values of $5-20 \mathrm{~g}_{\text {person }}{ }^{-1} \mathrm{day}^{-1}$ in 1961 to values of $26-47$ g person $^{-1}$ day $^{-1}$ in 2001 . With respect to animal fats, availability increased in Spain, Greece and particularly Italy, from 4, 5 and $9 \mathrm{~g}_{\text {person }}{ }^{-1} \mathrm{day}^{-1}$ in 1961 to 13, 8 and 30 gperson $^{-1}$ day $^{-1}$ in 2001, respectively. In France, animal fat supply increased from 29 to 52 g person $^{-1}$ day $^{-1}$ during the study period. On the contrary, animal fat supply has traditionally been low in African and Asiatic Mediterranean countries, and slight decreasing trends were observed from 1961 to 2001.

\section{Wine and other alcoholic beverages}

During the 1960s, wine supply was almost null in all African and Asiatic Mediterranean countries, intermediate in Greece and in Spain (92-162 g person ${ }^{-1}$ day $^{-1}$ in 1961), and very high in Italy and France (296-327 g person $^{-1}$ $\mathrm{day}^{-1}$ in 1961). Since then, it has decreased in all European Mediterranean countries, particularly in Italy and France, which presented in 2001 figures about half those found in 1961 (Fig. 5). In contrast, the supply of alcoholic beverages other than wine (data not shown) increased three- to six-fold in European Mediterranean countries, except France, with values ranging from $78 \mathrm{~g}$ person ${ }^{-1} \mathrm{day}^{-1}$ (Italy) to $195 \mathrm{~g}$ person $^{-1} \mathrm{day}^{-1}$ (Spain) in 2001. France presented the highest supply during the 1960s and experienced a 28\% decrease from then until 2001.

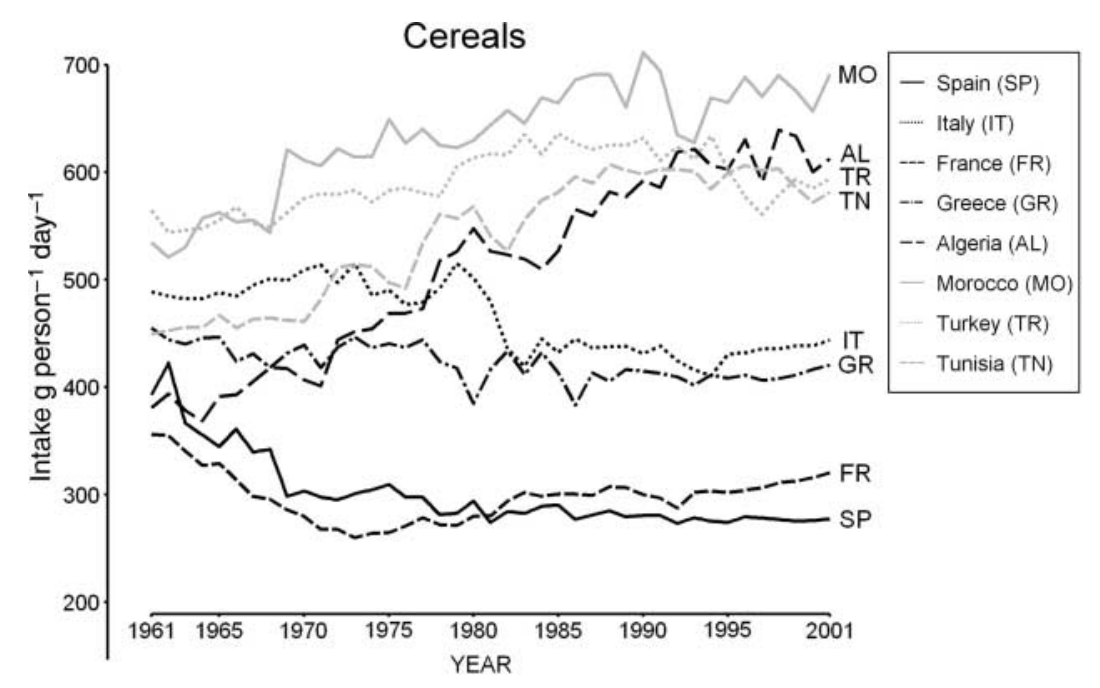

Fig. 3 Cereal supply in selected Mediterranean countries (European, African and Asian) from 1961 to 2001 (source: Food and Agriculture Organization food balance sheets) 


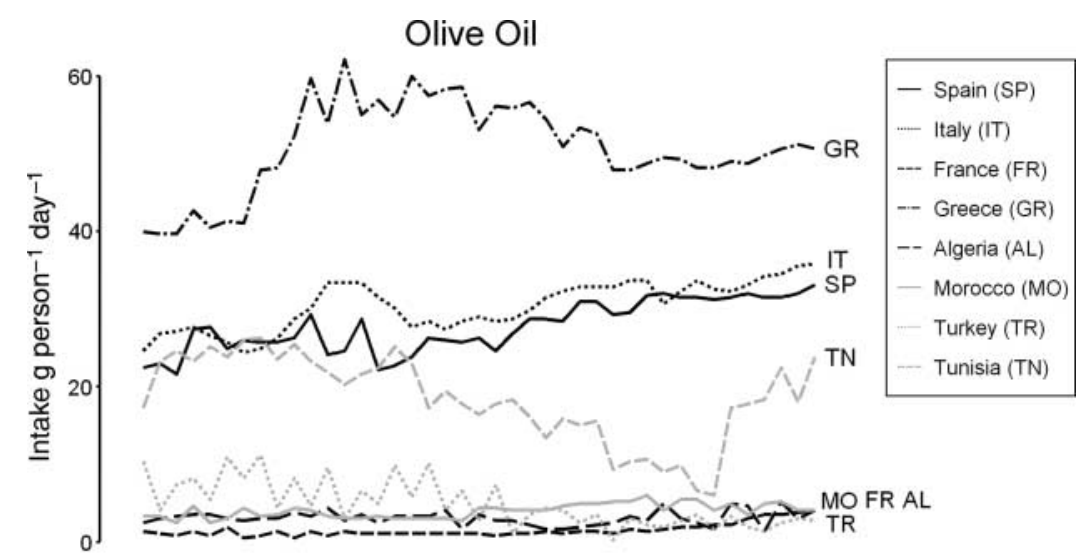

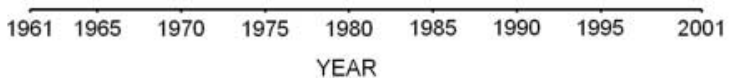

Fig. 4 Olive oil supply in selected Mediterranean countries (European, African and Asian) from 1961 to 2001 (source: Food and Agriculture Organization food balance sheets)

\section{Fish and seafood}

During the 1960s, fish and seafood supply was very low in African and Asiatic Mediterranean countries, intermediate in Italy, Greece and France, and high in Spain. It experienced an overall increase in all countries studied between 1961 and 2001, particularly Spain, which attained in 2001 a supply of $122 \mathrm{~g}$ person $^{-1}$ day $^{-1}$ (30\% higher than in France and 44\% higher than in Greece and Italy). Fish supply in African and Asiatic Mediterranean countries is still low, particularly in Algeria (Fig. 6).

\section{Milk and dairy products}

In 1961, milk and dairy product supply ranged from 78-130 g person $^{-1}$ day $^{-1}$ in Morocco, Tunisia and Algeria to 400-600 g person $^{-1}$ day $^{-1}$ in Italy, Turkey and France. During the surveyed period, it increased in all countries except Turkey and Morocco. Spain presented intermediate values during the 1990s, while France, Italy and Greece presented the highest $\left(>650\right.$ g person $^{-1} \mathrm{day}^{-1}$ ) (Fig. 7).

\section{Meats}

Meat availability was steadily low in African and Asiatic Mediterranean countries during the studied period, with values of $<50$ g person $^{-1}$ day $^{-1}$ in the 1960s and 5070 g person $^{-1}$ day $^{-1}$ in the 1990 s. On the contrary, meat availability increased dramatically in Italy, Greece and Spain, from around $60 \mathrm{~g}$ person ${ }^{-1} \mathrm{day}^{-1}$ in 1961 to 250323 g person $^{-1}$ day $^{-1}$ in 2001 . The highest increase was found in Spain; since 1993, it has attained supply levels higher than France. France presented a supply of $211 \mathrm{~g}$ person ${ }^{-1}$ day $^{-1}$ in 1961 and experienced a gradual increase throughout the surveyed period. Trends in red and poultry meat supply were similar in all countries, with parallel increases, except in African and Asiatic

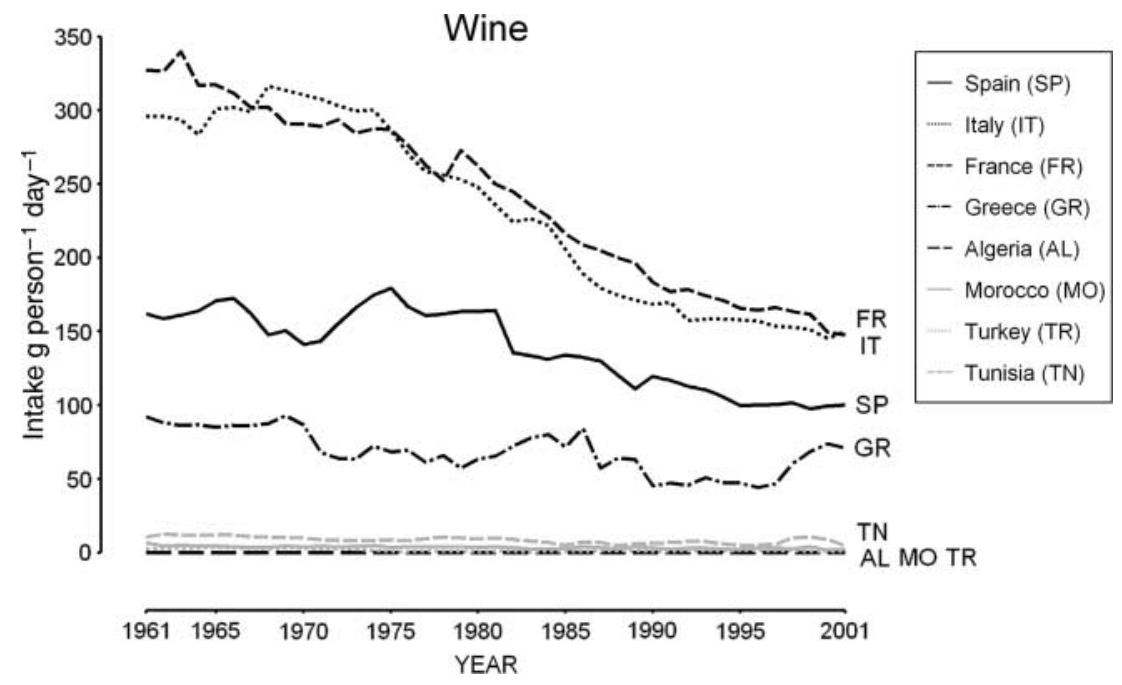

Fig. 5 Wine supply in selected Mediterranean countries (European, African and Asian) from 1961 to 2001 (source: Food and Agriculture Organization food balance sheets) 


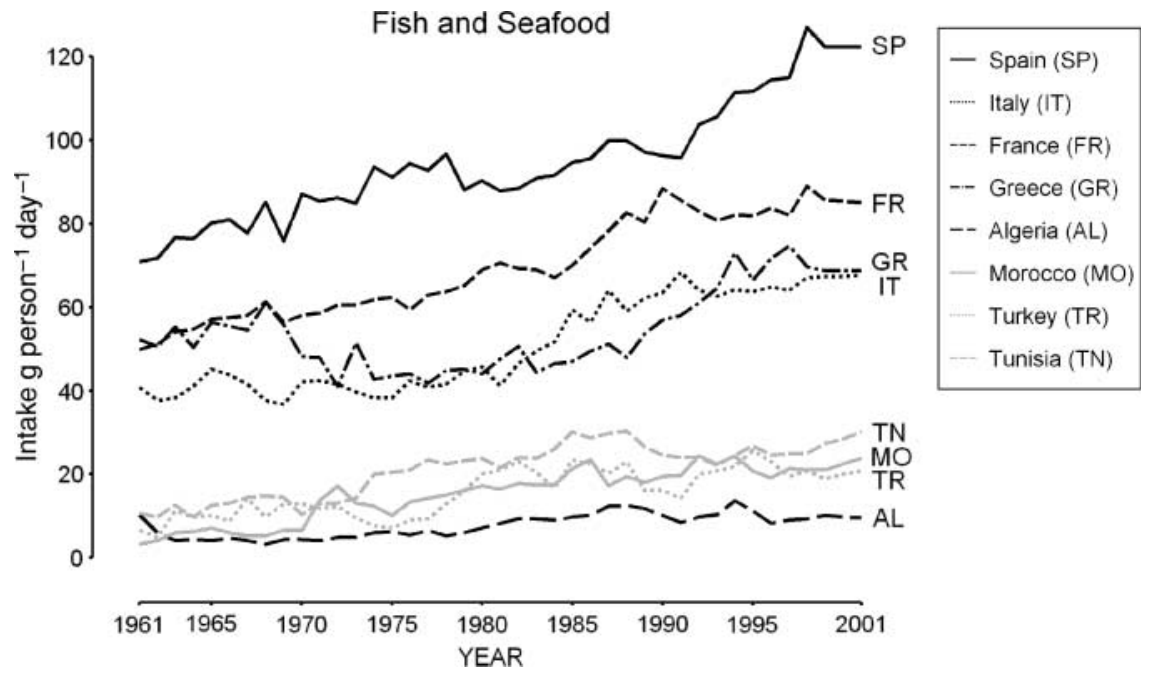

Fig. 6 Fish and seafood supply in selected Mediterranean countries (European, African and Asian) from 1961 to 2001 (source: Food and Agriculture Organization food balance sheets)

Mediterranean countries, where red meat availability remained steadily low whereas poultry experienced a 2.5- to five-fold increase (Fig. 8).

\section{Energy from animal products}

During the 1960s, the percentage of energy from animal products (data not shown) was relatively low in African and Asiatic Mediterranean countries (7-16\%) and in European Mediterranean ones (13-18\%), except France (>30\%). However, an almost two-fold increase was observed in Greece, Italy and Spain (22-27\%) by 2001. In France, $37 \%$ of energy came from animal products in the 1990s.

\section{Discussion}

Overall, FBS data show that food availability in the Mediterranean area was quite heterogeneous, and experienced important changes from 1961 to 2001. Between-country differences are and were present, probably linked to differences in natural and economic resources, as well as inherited cultural and religious traditions

In 1993, the 'traditional healthy Mediterranean diet pyramid' was proposed as a cultural model for a healthy diet, based on the dietary pattern found in Crete, much of the rest of Greece and southern Italy during the $1960 \mathrm{~s}^{16}$. Cereals and starchy roots were the base of this pyramid. However, figures based on FBS data show that, at this time, cereals were the base of food supply only in countries of the African and Asiatic Mediterranean area and not in those of the European Mediterranean area.

High fruit and vegetable intakes are also characteristic of the defined traditional Mediterranean diet. Favourable increasing trends were observed during the period 19612001, except for vegetable supply in Spain and especially

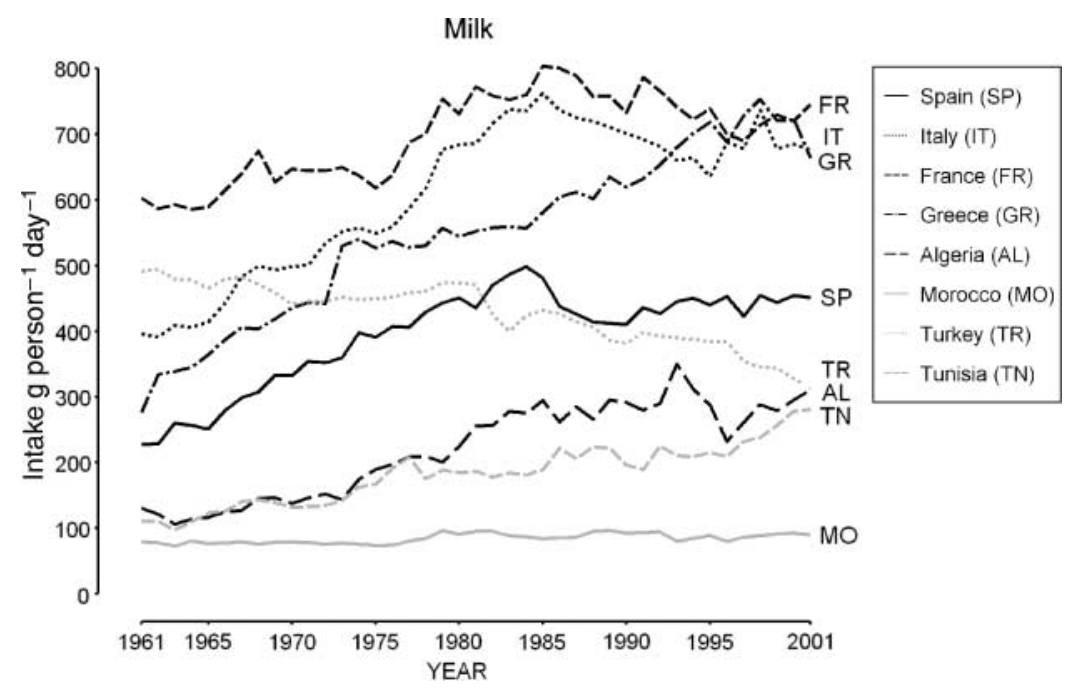

Fig. 7 Milk supply in selected Mediterranean countries (European, African and Asian) from 1961 to 2001 (source: Food and Agriculture Organization food balance sheets) 


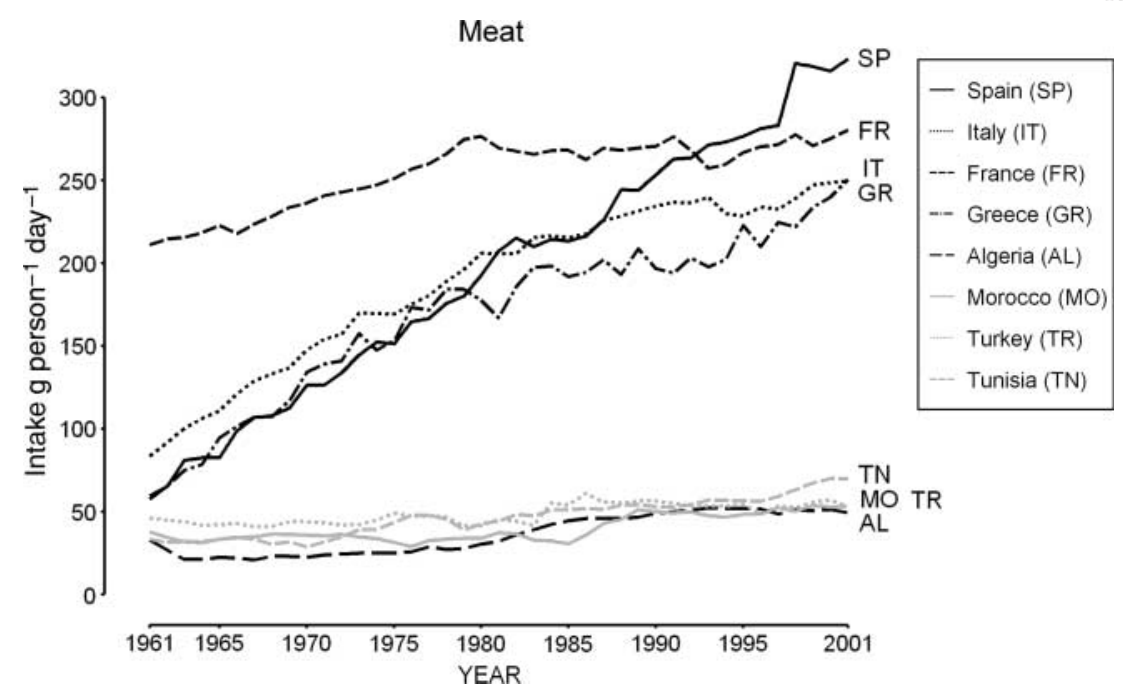

Fig. 8 Meat supply in selected Mediterranean countries (European, African and Asian) from 1961 to 2001 (source: Food and Agriculture Organization food balance sheets)

in France, and for fruit supply in Turkey. A five-fold difference was found in fruit and vegetable availability among Mediterranean countries throughout the period studied.

Olive oil is considered the primary source of fat in the traditional Mediterranean diet. However, 30-fold differences in olive oil supply were found among Mediterranean countries. Olive oil is the primary source of fat in Spain, Italy, Tunisia and especially Greece, while in the other Mediterranean countries studied, availability of olive oil was and is still very low. With respect to temporal trends in European Mediterranean countries, a very slight increase in olive oil supply and a very important increase in vegetable oils other than olive oil and animal fat supply were observed. Although these figures show a trend towards a more occidental pattern, Spain, Italy and particularly Greece still show a Mediterranean pattern of lipids intake that could be clearly differentiated from the pattern found in France and African and Asiatic Mediterranean countries.

Moderate wine intake, preferably with meals, is another feature of the Mediterranean diet. In European Mediterranean countries, the pattern of alcohol supply is approximating that typically found in Northern European countries, with a downwards trend for wine and an upwards trend for other alcoholic beverages, a pattern not characteristic of Mediterranean countries in the past. In African and Asiatic Mediterranean countries, alcohol supply from wine or other beverages has been steadily very low, probably due to religious practices.

FBS data show that fish supply was very high in Spain, intermediate in Italy and Greece, and very low in African and Asiatic Mediterranean countries. With respect to meat, a low supply was observed in the 1990s only in African and Asiatic Mediterranean countries. The steep increase in red meat supply in all European Mediterranean countries, especially Italy, Greece and Spain, shows a clear trend towards a Western diet. This increase, added to the increase in milk and dairy product availability in those countries, led to an increase in the proportion of energy from animal sources, although it did not reach the levels found in France.

It is well known that FBSs give only an estimate of the nationwide average food consumption. Quantities of food available for human consumption relate simply to those reaching the consumer, not to the amount of food actually consumed $^{13}$. Although waste on the farm and during distribution and processing is taken into consideration when elaborating FBS data, the degree of losses of edible food in the household - during storage, in preparation and cooking, as plate waste, as food for animals or thrown away - is not. Thus, the amount of food actually consumed tends to be lower than the quantity of food available, the degree of this difference depending on the food considered ${ }^{14}$. However, the FBS is recognised as a valid tool to make geographical comparisons as well as to analyse temporal trends since its methodology is reasonably well standardised among countries and over time ${ }^{13,14}$.

When comparing FBS data with data from other sources such as household budget surveys (HBSs) or dietary questionnaires obtained at family or individual level, similar conclusions on patterns of food intake and on temporal trends were found. In Spain, HBSs have been conducted since 1964 ${ }^{17}$. Although absolute estimates varied from $3 \%$ (fruits) to $45 \%$ (vegetables) when comparing HBS and FBS, food patterns and direction of changes during the studied period were very similar using both instruments. On the other hand, a recent study that used individual dietary questionnaires showed great intake variations among six Mediterranean countries (Greece, Italy, Algeria, Bulgaria, Egypt and Yugoslavia) 
and concluded that there is a Westernisation of dietary habits in the Mediterranean region ${ }^{18}$. Estimates of food intake from 24-hour dietary recalls were obtained in the cohort of the European Prospective Investigation into Cancer and Nutrition (EPIC) between 1995 and 2000 in Spain, Italy, France and Greece. As expected, estimates from recalls were lower than those from FBS data, especially for vegetables, cereals and dairy products. However, the proportion of intake from different food groups, as well as the ranking of countries by food group, was reasonably similar in both datasets ${ }^{19}$. Finally, when comparing FBS data with individual data from a national survey in Morocco $^{20}$ and a regional survey in Tunisia ${ }^{21}$, the same conclusions were drawn: diet in these African Mediterranean countries was based on vegetable and especially cereal intakes, with low intakes of meat, fish and wine.

Data on food availability have also been collected through national HBSs and harmonised in the context of the DAta Food NEtworking (DAFNE) project. This showed a decrease in fruit supply in Greece and Italy and of vegetable supply in Italy during the $1990 \mathrm{~s}^{22}$; moreover, comparing 1999 and 1988, there was a decrease in the availability of cereals, fresh vegetables and fresh fruit in Italy and Greece.

In summary, during the 1990s only Greece presented a pattern of food supply close to the defined 'traditional Mediterranean diet', while Italy and Spain maintained a high availability of fruits, vegetables and olive oil, but were losing other components. Turkey presented a Mediterranean-style pattern except in a key component, olive oil, whose supply was very low. France was the European Mediterranean country with a more Western pattern of food supply. An increase in the availability of meats, dairy products and alcoholic beverages other than wine, and a reduction in the availability of cereals and wine, was observed in European Mediterranean countries. The Gross National Product (GNP) seemed to be related to adherence to the traditional Mediterranean diet in these countries during the 1990s: France presented a GNP of $\$ 22490$ per capita in 1993 , and was followed by Italy (\$19849), Spain (\$13590) and Greece (\$7390) (www.wri.org). African and Asiatic Mediterranean countries, whose food supply was based mainly on cereals with low supplies of meat and fish, presented a GNP of $<\$ 2000$ per capita.

Given the growing available evidence of the beneficial effects of the traditional Mediterranean $\operatorname{diet}^{23-25}$, public health authorities and governments should seriously consider dietary trends in Mediterranean countries and try to implement agricultural policies and health promotion and preventive strategies that could help preserve healthy regional traditions and singularities, as well as correct unfavourable trends. These strategies should attempt to be compatible with the unavoidable global changes linked to the present rapid technological and socio-cultural development.

\section{Acknowledgements}

This study received financial support from the ISCIII Network (RCESP, C03/09).

Conflict of interest: none declared.

\section{References}

1 Willett WC, Sacks F, Trichopoulou A, Drescher G, FerroLuzzi A, Helsing E, et al. Mediterranean diet pyramid: a cultural model for healthy eating. American Journal of Clinical Nutrition 1995; 61(Suppl.): 1402S-6S.

2 Trichopoulou A, Lagiou P. Healthy traditional Mediterranean diet: an expression of culture, history and lifestyle. Nutrition Reviews 1997; 55: 383-9.

3 Keys A, ed. Seven Countries: A Multivariate Analysis of Death and Coronary Heart Diseases. Cambridge, MA: Harvard University Press, 1980.

4 Helsing E. Traditional diets and disease patterns of the Mediterranean, circa 1960. American Journal of Clinical Nutrition 1995; 61(Suppl.): 1329S-37S.

5 American Institute for Cancer Research (AICR)/World Cancer Research Fund (WCRF). Food, Nutrition and the Prevention of Cancer. A Global Perspective. Washington, DC: AICR/WCRF, 1997.

6 McDermott JH. Antioxidant nutrients: current dietary recommendations and research update. Journal of the American Pharmaceutical Association 2000; 40: 785-99.

7 De Lorgeril M, Salen P. Mediterranean type of diet for the prevention of coronary heart disease. International Journal for Vitamin and Nutrition Research 2001; 71: 166-72.

8 Simopoulos AP. The Mediterranean diets: what is so special about the diet of Greece? The scientific evidence. Journal of Nutrition 2001; 131(Suppl.): 3065S-73S.

9 Trichopoulou A, Costacou T, Bamia C, Trichopoulos D. Adherence to a Mediterranean diet and survival in a Greek population. New England Journal of Medicine 2003; 348: 2599-608.

10 Keys A, Keys M. How to Eat Well and Stay Well: The Mediterranean Way. New York: Doubleday \& Co., 1975.

11 Ferro-Luzzi A, Sette S. The Mediterranean diet: an attempt to define its present and past composition. European Journal of Clinical Nutrition 1989; 43(Suppl.): 13-29.

12 Nestle M. Mediterranean diets: historical and research overview. American Journal of Clinical Nutrition 1995; 61(Suppl.): 1313S-20S.

13 Gibson RS. Principles of Nutritional Assessment. Oxford: Oxford University Press, 1990.

14 Becker W, Helsing E, ed. Food and Health Data: Their Use in Nutrition Policy Making. Regional Publication, European Series No. 34. Copenhagen: World Health Organization Regional Office for Europe, 1991.

15 Food and Agriculture Organization. Food Balance Sheets [online]. Available at http://www.fao.org. Accessed 15 January 2004.

16 Gifford KD, Drescher G, Jenkins NH, eds. Diets of the Mediterranean: A Summary Report of the 1993 International Conference on the Diets of the Mediterranean, Cambridge, MA, 20-23 January 1993. Boston, MA: Oldways Preservation \& Exchange Trust and Harvard School of Public Health, 1993.

17 Instituto Nacional de Estadística (INE). Encuesta de presupuestos familiares 1990-91. Estudio nacional de nutrición y alimentación. Madrid: INE, 1990.

18 Karamanos B, Thanopoulou A, Angelico F, Assaad-Khalil S, Barbato A, Del Ben $\mathrm{M}$, et al. Nutritional habits in the Mediterranean Basin. The macronutrient composition of diet and its relation with the traditional Mediterranean diet. Multi- 
centre study of the Mediterranean Group for the Study of Diabetes (MGSD). European Journal of Clinical Nutrition 2002; 56: 983-91

19 Slimani N, Fahey M, Welch AA, Wirfalt E, Stripp C, Bergstrom $\mathrm{E}$, et al. Diversity of dietary patterns observed in the European Prospective Investigation into Cancer and Nutrition (EPIC) project. Public Health Nutrition 2002; 5: 1311-28.

20 Benjelloun S. Nutrition transition in Morocco. Public Health Nutrition 2002; 5: 135-40.

21 Gharbi M, Hani AB, Aouidet A, Akrout M, Nasraoui A, Tritar B. Dietary intake in the urban and rural populations of the Cap-Bon. Revue d'Epidemiologie et de Sante Publique 1998; 46: $164-75$.
22 Trichopoulou A, Naska A, Costacou T, DAFNE III Group. Disparities in food habits across Europe. Proceedings of the Nutrition Society 2002; 61: 553-8.

23 Trichopoulou A, Naska A, Antoniou A, Friel S, Trygg K, Turrini A. Vegetable and fruit: the evidence in their favour and the public health perspective. International Journal for Vitamin and Nutrition Research 2003; 73: 63-9.

24 Panagiotakos DB, Pitsavos C, Polychronopoulos E, Chrysohoou C, Zampelas A, Trichopoulou A. Can a Mediterranean diet moderate the development and clinical progression of coronary heart disease? A systematic review. Medical Science Monitor 2004; 10: 193-8.

25 La Vecchia C. Mediterranean diet and cancer. Public Health Nutrition 2004; 7: 965-8. 